\title{
COMPOSIÇÃO FLORÍSTICA E CARACTERIZAÇÃO DO ESTADO DE CONSERVAÇÃO DE NASCENTES NO CENTRO-LESTE DA BACIA HIDROGRÁFICA DO RIO ITAPICURU, SEMIÁRIDO DA BAHIA
}

\author{
Janisson Batista de Jesus ${ }^{1 *}$, Lucas Souza Oliveira ${ }^{2}$, Dráuzio Correia Gama ${ }^{3}$ \\ ${ }^{1 *}$ Universidade Federal do Rio Grande do Sul, Programa de Pós-Graduação em Sensoriamento Remoto, Porto Alegre, Rio \\ Grande do Sul, Brasil - janisson.eng@gmail.com \\ ${ }^{2}$ Faculdade Dom Luiz de Orleans e Bragança-BA, curso de Engenharia Agronômica, Ribeira do Pombal, Bahia, Brasil - \\ agrolucas125@gmail.com \\ ${ }^{3}$ Universidade Estadual do Sudoeste da Bahia, Programa de Pós-Graduação em Ciências Florestais, Vitória da Conquista, \\ Bahia, Brasil - drauzio1981@gmail.com
}

Recebido para publicação: 29/09/2017- Aceito para publicação: 06/03/2018

\begin{abstract}
Resumo
Os mananciais são fundamentais para a hidrologia das bacias hidrográficas. Seu monitoramento e conservação são importantes, principalmente no semiárido, onde a oferta de água é escassa. O objetivo deste trabalho foi mapear as nascentes existentes na região semiárida da Bahia, porção centro-leste da bacia hidrográfica do rio Itapicuru, e caracterizar seu estado de conservação e as espécies de ocorrência em sua área de preservação permanente. O trabalho foi realizado através de idas a campo nos municípios de Cipó, Nova Soure e Tucano. Foram georreferenciadas todas as nascentes localizadas na bacia hidrográfica do rio Itapicuru, e foram identificados e contabilizados todos os indivíduos e espécies existentes num raio de $50 \mathrm{~m}$. Também, foram registradas as formas de uso do solo e avaliado o seu estado de degradação em preservada, perturbada ou degradada. Todas as 14 nascentes localizadas eram pontuais, sendo a pastagem a principal forma de uso. Não existiam nascentes preservadas. A espécie mais observada foi Poincianella pyramidalis (catingueira/nativa), seguida de Mangifera indica (mangueira/exótica). O estudo identificou alto grau de degradação das nascentes, atestando a falta ou inadequado manejo dos recursos hídricos e alertando à necessidade de intervenção de práticas de manejo na bacia hidrográfica.

Palavras-chave: Manejo de bacias hidrográficas, mata ciliar, caatinga, legislação florestal.
\end{abstract}

\begin{abstract}
Floristic composition and characterization of the conservation state of springs from the central east portion of the Itapicuru river watershed in the Bahia semiarid. Springs are fundamental for the hydrology of watersheds. Their monitoring and conservation are important, mainly in the semiarid, where the water supply is scarce. The objective of this study was to map springs from the semiarid region of Bahia, central east portion of the Itapicuru river watershed, and characterize their conservation state and occurrence species in the permanent preservation area. The study was carried out through field visits in the municipalities of Cipó, Nova Soure, and Tucano. All springs located in the Itapicuru river watershed were georeferenced, and all the existing individuals and species were identified and counted in the radius of $50 \mathrm{~m}$. Also, the forms of using the soil were recorded and their degradation status was assessed as preserved, disturbed or degraded. All 14 springs located were punctual, and pasture was the main form of using. there are no preserved springs. The most observed species was Poincianella pyramidalis (catingueira/native), followed by Mangifera indica (mangueira/exotic). The study identified high degree of springs degradation, attesting to the lack or inadequate springs management and alerting to the need of intervention of river basin management practices.

Keywords: Watershed management, riparian forest, caatinga, forestry legislation.
\end{abstract}

\section{INTRODUÇÃO}

As nascentes são importantes mananciais hídricos, ambientes singulares de grande complexidade e essenciais para a formação dos corpos hídricos (SANTANA et al., 2016). Devido à sua relevância nos processos ambientais, hidrológicos e ecológicos dentro das bacias hidrográficas, as quais são as unidades do planejamento nacional, a legislação brasileira, por meio da Lei $n^{\circ} 12.651$ de 25 de maio de 2012, estabeleceu que esses espaços devem ser áreas de preservação permanentemente (APP) e ter um raio mínimo de 50 metros (BRASIL, 2012).

Para garantir a proteção dessas áreas, é imprescindível a presença da vegetação ciliar, que, além de evitar os processos de degradação, também possui função hidrológica associada à nascente (VENZEL et al., 2016). Atuam, assim, com importantes serviços ambientais, principalmente os de proteção do solo e dos corpos hídricos (MAGALHÃES et al., 2012). Entretanto, as atividades de desmatamento e diversos usos do solo nas APPs das nascentes

FLORESTA, Curitiba, PR, v. 48, n. 2, p. 245-254, abr/jun 2018

Jesus. J. B. et.al.

ISSN eletrônico 1982-4688

DOI: $10.5380 /$ rf.v48 i 2.55540 
causam fortes impactos e são consideradas grandes problemas ambientais, resultando na sua degradação (VENZEL et al., 2016) e comprometendo a qualidade e o volume de suas águas (MAGALHÃES et al., 2012).

Por causa desse desequilíbrio resultante da relação entre a exploração excessiva e a proteção da mata ciliar, é necessário adotar medidas que deem suporte às ações de planejamento ambiental e de manejo das bacias hidrográficas, garantindo a preservação ou a restauração florestal (FERREIRA et al., 2011). É necessário identificar as nascentes e realizar o diagnóstico dessas áreas a fim de reconhecer o seu estado de conservação e as formas de uso e ocupação do seu solo e, consequentemente, a necessidade de recuperação.

Esse contexto hídrico é ainda mais crítico quando se trata da região semiárida brasileira, que é caracterizada pela ocorrência de períodos de seca, alta evapotranspiração, e solos rasos de baixa capacidade de retenção de água. Esses fatores tornam o ambiente e os ecossistemas naturais ainda mais sensíveis à degradação ao serem associados a práticas de retirada da cobertura vegetal e uso inadequado da terra, devido à exploração predatória da biomassa da caatinga (PETTA et al., 2013).

Alerta-se para o semiárido do Brasil, pois seus recursos naturais e bacias hidrográficas foram degradados, particularmente em virtude da remoção da vegetação natural. Consequentemente, o ciclo hidrológico também é influenciado, resultando numa nova dinâmica ambiental caracterizada pela desertificação (ALVES et al., 2015). Esse risco decorre também da atividade humana. A má gestão no uso do solo aliada à intensiva expansão da agricultura assumiu tanto destaque que vários estudos analisam a susceptibilidade de determinadas localidades a tal processo. Entre elas está a porção semiárida da bacia hidrográfica do rio Itapicuru, que possui áreas delimitadas com alta susceptibilidade (VIEIRA et al., 2015).

Esta situação de degradação ambiental das APP pelo uso inadequado e ocupação humana se estabelece mesmo com a existência de legislações estaduais específicas na Bahia, que respaldam a proteção das nascentes e das matas ciliares, compreendendo o espaço necessário para sua preservação, conforme a Lei no 10.431 de 20 de dezembro de 2006 (BAHIA, 2006) que dispõe sobre a política de meio ambiente e de proteção à biodiversidade do estado da Bahia. Além disso, a Lei n 11.612 de 08 de outubro de 2009 (BAHIA, 2009) trata da política estadual de recursos hídricos, do sistema estadual de gerenciamento de recursos hídricos e dá outras providências, que garantem a implementação de programas e projetos de proteção ambiental das bacias hidrográficas, contemplando a recuperação de áreas degradadas, preservação, conservação e recuperação de matas ciliares e nascentes e das áreas de recargas no Plano Estadual de Recursos Hídricos através do Plano de Bacias Hidrográficas.

Apesar da grande importância da manutenção e conservação das nascentes, em destaque no semiárido, observase a ausência de estudos que visam ao mapeamento e à caracterização dessas fontes hídricas, sendo verificados alguns escassos estudos sobre outros biomas, principalmente Mata Atlântica. Sendo assim, o objetivo deste trabalho foi mapear as nascentes existentes na região semiárida da Bahia, porção centro-leste da bacia hidrográfica do rio Itapicuru, e caracterizar sua florística, identificando as espécies existentes em sua área de preservação permanente e seu estado de conservação a fim de observar em quais níveis de degradação ou preservação se encontram.

\section{MATERIAL E MÉTODOS}

\section{Área de estudo}

O estudo foi realizado na bacia hidrográfica do rio Itapicuru (Bahia), situada entre as entre as latitudes $10^{\circ}$ e $12^{\circ} \mathrm{S}$ e longitudes $41^{\circ}$ e $37^{\circ} \mathrm{W}$, e possui uma área de $38.664 \mathrm{~km}^{2}$, que abrange a região nordeste do estado da Bahia e 55 municípios. A região apresenta três condições climáticas: no trecho inferior da bacia hidrográfica, o clima é do tipo úmido a subúmido, com precipitações de 1000 a $1400 \mathrm{~mm}$; na parte superior da Região, na Chapada da Diamantina, o clima varia do tipo subúmido ao seco, com totais pluviométricos até $900 \mathrm{~mm}$; e na região semiárida, há chuvas anuais inferiores a $700 \mathrm{~mm}$. Esta última é a mais representativa (81\% da área) e ocupa a parte central da Região de Planejamento e Gestão das Águas (RPGA) (INEMA, 2017), tendo de 7 a 8 meses de seca (PURIFICAÇÃO et al., 2016).

O foco do trabalho ocorreu na porção centro-leste dessa unidade de planejamento, entre os municípios de Cipó, Nova Soure e Tucano (Figura 1). Essa região é compreendida climaticamente como semiárida, com vegetação natural de Caatinga. A área tem os tipos Latossolo vermelho amarelo e Planossolo como solo característicos (EMBRAPA, 2006) e é, ainda, caracterizada por apresentar fontes de águas termais e ter um forte aspecto turístico. 


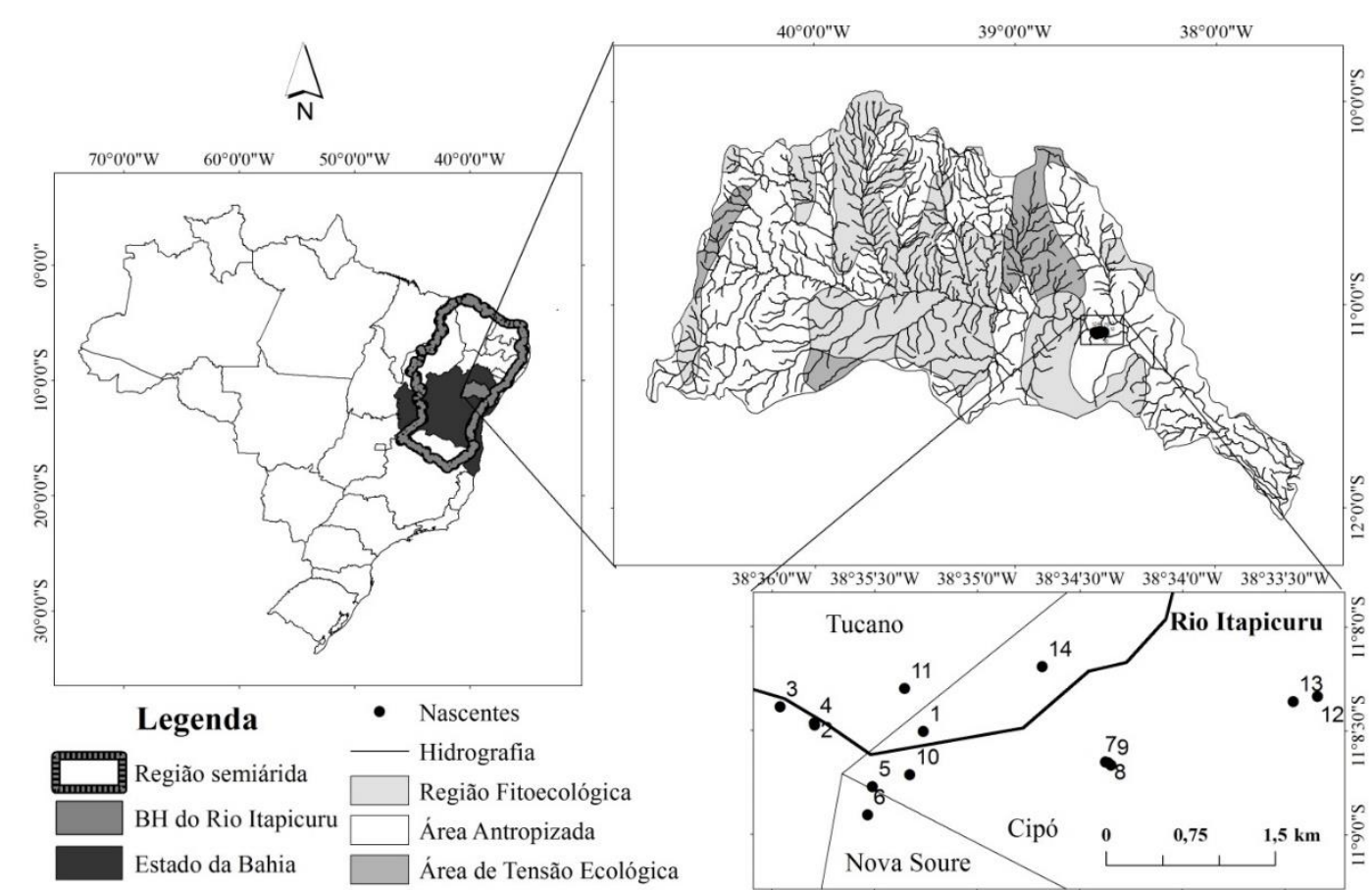

Figura 1. Localização do estado da Bahia, da região semiárida, da bacia hidrográfica do rio Itapicuru, juntamente com a sua rede de drenagem, e das nascentes mapeadas distribuídas entre os municípios de Cipó, Nova Soure e Tucano. Fonte: Instituto Nacional do Semiárido (2017).

Figure 1. Location of the state of Bahia, the semiarid region, the Itapicuru river watershed, along with its drainage network, and the mapped springs distributed amongs the municipalities of Cipó, Nova Soure and Tucano. Source: Nacional Institute of Semiarid (2017).

\section{Mapeamento, levantamento florístico e caracterização do estado de conservação das nascentes}

O levantamento florístico e a caracterização do estado de conservação das nascentes foram realizados em todo o perímetro de $50 \mathrm{~m}$ de cada nascente, constituído como APP conforme o Código Florestal (Lei ${ }^{\circ}$ 12.651), sendo a área delimitada no entorno de nascentes e de olhos d'água perenes, qualquer que fosse sua situação topográfica. Para isso, o mapeamento através do georreferenciamento das nascentes foi realizado diretamente por meio de idas a campo realizadas entre os meses de outubro e dezembro de $2016 \mathrm{com}$ o uso do aparelho GPS Garmin, modelo Etrex 30, precisão média de cerca de $3 \mathrm{~m}$, sendo registrados os dados de latitude, longitude e altitude de cada nascente localizada. No levantamento florístico, as espécies foram identificadas por meio de consulta a literaturas especializadas (LORENZI, 2008, 2009) e nomeadas cientificamente de acordo com a AGP IV (2016). Todos os indivíduos foram contabilizados e registrados.

As nascentes foram diagnosticadas quanto ao uso do solo (pastagem, agricultura, vegetação natural ou outros encontrados nas idas a campo) no raio mínimo de $50 \mathrm{~m}$ da sua APP. Foram, então, classificadas quanto ao tipo de reservatório em: pontuais (Pt), em que o fluxo d'água ocorre em um único local do terreno; ou difusas (Di), em que a ocorrência do fluxo não se dá em um ponto específico do terreno, apresentando vários pontos comuns de saída superficial d'água. Também, foram classificadas quanto ao estado de conservação em: preservada (Pr), em que a APP da nascente se apresentava totalmente coberta por vegetação natural, sem presença de impactos ou degradação; perturbadas $(\mathrm{Pe})$, que não tinham vegetação recobrindo totalmente a $\mathrm{APP}$, mas apresentavam um bom estado de conservação; e degradada (Dr), com a ocorrência de alto grau de perturbação em sua APP, muito pouco vegetadas ou sem vegetação, com forte impacto antrópico, considerando essa mesma área do seu entorno, segundo Castro e Lopes (2001), e de acordo com os estudos similares desenvolvidos por Pinto et al. (2005) e Ferreira et al. (2011), que consideraram as mesmas classificações.

\section{RESULTADOS}

Caracterização das nascentes quanto ao tipo de reservatório e estado de conservação

Foram localizadas 14 nascentes na área, e foi observado que as nascentes 2, 3 e 4 estavam mais próximas do curso principal do rio Itapicuru. Notou-se uma variação altimétrica de 19 m entre as nascentes identificadas.

FLORESTA, Curitiba, PR, v. 48, n. 2, p. 245-254, abr/jun 2018

Jesus. J. B. et.al.

ISSN eletrônico 1982-4688

DOI: $10.5380 /$ rf.v48 i2.55540 
Além disso, todas foram caracterizadas quanto ao tipo de reservatório como pontuais, posicionadas de forma isolada uma das outras, mesmo que algumas estivessem próximas (7 e 8). Não houve, portanto, nascentes difusas. A análise do estado de conservação das nascentes mapeadas constatou que oito nascentes estavam degradadas e seis estavam perturbadas, não havendo nascente preservada (Tabela 1).

Tabela 1. Identificação geográfica e caracterização das nascentes quanto ao fluxo de água (tipo de reservatório) e estado de conservação.

Table 1. Geographical identification and characterization of springs in relation to the water flow (type of reservoir) and conservation status.

\begin{tabular}{|c|c|c|c|c|c|c|c|c|}
\hline \multirow[t]{2}{*}{$\mathbf{N}^{\circ}$} & \multicolumn{2}{|c|}{$\begin{array}{l}\text { Coordenadas UTM 24S } \\
\text { (SIRGAS 2000) }\end{array}$} & \multirow{2}{*}{$\begin{array}{l}\text { Altitude } \\
\quad(\mathbf{m})\end{array}$} & \multicolumn{2}{|c|}{ Reservatório } & \multicolumn{3}{|c|}{ Nível de Conservação } \\
\hline & $\mathbf{X}$ & $\mathbf{Y}$ & & $\mathbf{P t}$ & Di & Pr & $\mathbf{P e}$ & Dr \\
\hline 1 & 544891,2748 & 8768054,3143 & 134 & $\mathrm{x}$ & & & $\mathrm{x}$ & \\
\hline 2 & 544051,5284 & 8768373,6762 & 132 & $\mathrm{x}$ & & & $\mathrm{x}$ & \\
\hline 3 & 543743,8827 & 8768537,4975 & 134 & $\mathrm{x}$ & & & $\mathrm{x}$ & \\
\hline 4 & 544558,9981 & 8767727,0433 & 144 & $\mathrm{x}$ & & & & $\mathrm{x}$ \\
\hline 5 & 544564,5973 & 8767828,3955 & 139 & $\mathrm{x}$ & & & $\mathrm{x}$ & \\
\hline 6 & 544519,9677 & 8767576,9002 & 150 & $\mathrm{x}$ & & & & $\mathrm{x}$ \\
\hline 7 & 546631,9908 & 8768048,4747 & 133 & $\mathrm{x}$ & & & & $\mathrm{x}$ \\
\hline 8 & 546654,1199 & 8768039,5354 & 134 & $\mathrm{x}$ & & & & $\mathrm{x}$ \\
\hline 9 & 546680,1744 & 8768018,3044 & 135 & $\mathrm{x}$ & & & & $\mathrm{x}$ \\
\hline 10 & 544895,0488 & 8767932,3701 & 140 & $\mathrm{x}$ & & & & $\mathrm{x}$ \\
\hline 11 & 548455,6311 & 8769133,7294 & 131 & $\mathrm{x}$ & & & $\mathrm{x}$ & \\
\hline 12 & 548512,2043 & 8768629,3008 & 140 & $\mathrm{x}$ & & & $\mathrm{x}$ & \\
\hline 13 & 548294,6565 & 8768584,7817 & 136 & $\mathrm{x}$ & & & & $\mathrm{x}$ \\
\hline \multirow[t]{2}{*}{14} & 546070,2414 & 8768894,2526 & 135 & $\mathrm{x}$ & & & & $\mathrm{x}$ \\
\hline & & & Total & 14 & 0 & 0 & 6 & 8 \\
\hline
\end{tabular}

Pt: pontual; Di: difusa; Pr: preservada; Pe: perturbada; Dr: degradada.

Ao analisar o uso e a ocupação do solo na área de preservação permanente de cada nascente, foi observado que sete contavam com a presença de alguma espécie nativa, cinco tinham atividade agrícola e dez eram submetidas à pastagem (Tabela 2). De forma mais detalhada, as principais atividades de pastagem estavam associadas à criação de ovinos e bovinos, encontrados em $50 \%$ das nascentes. O uso da APP para a agricultura também foi característico, com plantação de hortaliças, frutíferas e cana-de-açúcar.

Tabela 2. Formas de uso e ocupação do solo na área de preservação permanente (APP) das nascentes mapeadas. Table 2. Forms of using and occupying the soil in the permanent preservation area (PPA) of the springs mapped.

Formas de uso e ocupação do solo

\begin{tabular}{cccccc}
$\mathbf{N}^{\circ}$ & $\begin{array}{c}\text { Vegetação } \\
\text { natural }\end{array}$ & Agricultura & Pastagem & Outros & Informações relevantes \\
\hline 1 & $\mathrm{x}$ & & $\mathrm{x}$ & & criação de bovinos e equinos \\
2 & $\mathrm{x}$ & $\mathrm{x}$ & & criação de bovinos \\
3 & $\mathrm{x}$ & $\mathrm{x}$ & & criação de ovinos \\
4 & $\mathrm{x}$ & $\mathrm{x}$ & $\mathrm{x}$ & Piscicultura & plantação de hortaliças \\
5 & $\mathrm{x}$ & $\mathrm{x}$ & & plantação de frutíferas \\
6 & $\mathrm{x}$ & & $\mathrm{x}$ & sem vazão \\
7 & & & & criação de ovinos
\end{tabular}




\begin{tabular}{|c|c|c|c|c|c|}
\hline 8 & & & $\mathrm{x}$ & & criação de ovinos \\
\hline 9 & & & $\mathrm{x}$ & & criação de ovinos e bovinos \\
\hline 10 & $\mathrm{x}$ & & & Desmatada & sem uso ou ocupação \\
\hline 11 & & $\mathrm{x}$ & & & \\
\hline 12 & & $\mathrm{x}$ & $\mathrm{x}$ & & criação de equinos \\
\hline 13 & & $\mathrm{x}$ & $\mathrm{x}$ & & canalizada, canavial, criação de bovinos \\
\hline 14 & & & & Desmatada & sem vazão e sem uso ou ocupação \\
\hline Total & 7 & 5 & 10 & 3 & - \\
\hline
\end{tabular}

As nascentes 6 e 14 merecem destaque por apresentarem alto grau de degradação em um estado sem fluxo de água e, portanto, sem vazão. Não houve qualquer atividade ou alguma forma de uso em seu entorno, estando apenas desmatada. Além dessas, as nascentes 4 e 13 tiveram seu fluxo hídrico natural alterado por atividades de canalização da água superficial para a atividade de piscicultura e canavieira. As nascentes 1, 2, 3 e 4 estavam mais próximas ao curso do rio Itapicuru, sendo ocupadas por vegetação natural. Relacionam-se, assim, com a proximidade da mata ciliar, sem forte pressão do desmatamento para a implantação da agricultura, mas, mesmo assim, sofrem impacto da pastagem exatamente pela influência do rio, que fornece mais água. Enquanto isso, as nascentes 12 e 13 foram totalmente alteradas para agricultura e pastagem, mesmo sendo as mais afastadas do rio Itapicuru.

\section{Composição florística na APP das nascentes}

O levantamento florístico na APP mostrou que foram identificadas 18 espécies, distribuídas em 10 famílias, sendo a Fabaceae a mais representativa. Da diversidade observada, seis espécies eram consideradas exóticas e 14, nativas.

Tabela 3. Composição florística da área de preservação permanente (APP) das nascentes analisadas, com nome científico, seu respectivo nome popular, família botânica, origem e grupo ecológico.

Table 3. Floristic composition on the permanent preservation area (PPA) of the springs analyzed, with scientific name, its respective popular name, botanical family, origin and ecological group.

\begin{tabular}{|c|c|c|c|}
\hline $\begin{array}{l}\text { Famílias } \\
\text { Botânicas }\end{array}$ & Nome popular & Nome científico & Origem \\
\hline \multirow{2}{*}{ Anacardeaceae } & mangueira & Mangifera indica $\mathrm{L}$. & Exo \\
\hline & umbuzeiro & Spondias tuberosa Arruda & Nat \\
\hline Arecaceae & coqueiro & Cocos nucifera $\mathrm{L}$ & Exo \\
\hline Bignoniaceae & caraíba & Tabebuia aurea (Silva Manso) Benth. \& Hook. & Nat \\
\hline Capparaceae & trapiá & Crateva tapia $\mathrm{L}$ & Nat \\
\hline \multirow{8}{*}{ Fabaceae } & algaroba & Prosopis juliflora (Sw) DC L. & Exo \\
\hline & marizeiro & Geoffroea spinosa Jacq. & Nat \\
\hline & catingueira & Poincianella pyramidalis (Tul.) L.P.Queiroz & Nat \\
\hline & ingá & Inga spp. & Nat \\
\hline & itapicuru & Barnebydendron riedelii (Tul.) J.H.Kirkbr. & Nat \\
\hline & jurema-preta & Mimosa tenuiflora (Willd.) Poir. & Nat \\
\hline & sena & Senna spectabilis var. excelsa (Schrad.) H.S.Irwin \& Barneby & Nat \\
\hline & tamarindo & Tamarindus indica $\mathrm{L}$. & Exo \\
\hline Musaceae & bananeira & Musa spp. & Exo \\
\hline Rhamnaceae & juazeiro & Ziziphus joazeiro Mart. & Nat \\
\hline Rutaceae & laranjeira & Citrus sp. & Exo \\
\hline Sapindaceae & saboneteira & Sapindus saponaria $\mathrm{L}$. & Nat \\
\hline
\end{tabular}

FLORESTA, Curitiba, PR, v. 48, n. 2, p. 245-254, abr/jun 2018

Jesus. J. B. et.al. 
Ao todo, foram registrados 236 indivíduos. A espécie com maior quantidade de indivíduos foi Poincianella pyramidalis (56), seguida de Mangifera indica (40) e Mussa spp. (36) (Tabela 4). As espécies Ziziphus joazeiro e Mangifera indica foram as que estiveram na maior quantidade de nascentes (5 cada). Por nascente, observou-se que as nascentes 1, 2 e 3 tiveram a maior quantidade de indivíduos (46, 34 e 48, respectivamente) e a maior diversidade de espécies (6 cada).

Tabela 4. Número de indivíduos por espécie para cada nascente mapeada.

Table 4. Number of individuals per species for each spring mapped.

\begin{tabular}{|c|c|c|c|c|c|c|c|c|c|c|c|c|c|c|}
\hline \multirow{2}{*}{ Espécies } & \multicolumn{13}{|c|}{ Nascente } & \multirow{2}{*}{ Total } \\
\hline & 1 & 2 & 3 & 4 & 5 & 6 & $7 / 8$ & 9 & 10 & 11 & 12 & 13 & 14 & \\
\hline algaroba & & 1 & & & & & 4 & & & & & & & 5 \\
\hline bananeira & & & & & & & & & & & & 36 & & 36 \\
\hline caraíba & & & 1 & & 1 & & & & & & & & & 2 \\
\hline catingueira & 14 & 20 & 22 & & & & & & & & & & & 56 \\
\hline coqueiro & & & & & 4 & & 1 & & & & 1 & & & 6 \\
\hline ingá & 14 & 5 & 13 & 1 & & & & & & & & & & 33 \\
\hline itapicuru & & & 8 & & & 1 & & & & & & & & 9 \\
\hline juazeiro & 2 & 1 & 1 & 1 & & & & & 4 & & & & & 9 \\
\hline jurema-preta & & & & 2 & & & & & 1 & & & & & 3 \\
\hline laranjeira & & & & & 5 & & & & & & & & & 5 \\
\hline mangueira & & & & & 11 & & 4 & 1 & & 20 & 4 & & & 40 \\
\hline marizeiro & 3 & 1 & & & & & & & & & & & & 4 \\
\hline quixabeira & 9 & & 3 & & & & & & & & & & & 12 \\
\hline saboneteira & 4 & & & & & & & & & & & & & 4 \\
\hline sena & & 6 & & & & & & & 1 & & & & & 7 \\
\hline tamarindo & & & & & 1 & & & & & & & & & 1 \\
\hline trapiá & & & & & 2 & & & & 1 & & & & & 3 \\
\hline umbuzeiro & & & & & & 1 & & & & & & & & 1 \\
\hline Total & 46 & 34 & 48 & 4 & 24 & 2 & 9 & 1 & 7 & 20 & 5 & 36 & 0 & 236 \\
\hline
\end{tabular}

Já as espécies com menor representatividade foram Spondias tuberosa e Tamarindus indica, ambas com 1 indivíduo. Além disso, 13 das 18 espécies não apresentaram mais de 10 indivíduos ao todo. Por nascente, as nascentes 6, 9 e 14 apresentaram a menor quantidade de indivíduos (2, 1 e 0, respectivamente); a última encontrando-se totalmente desmatada.

\section{DISCUSSÃO}

O nível de degradação das nascentes mapeadas na região estudada da bacia hidrográfica do rio Itapicuru é alarmante, pois há um forte impacto das atividades humanas nas áreas que deveriam estar reservadas apenas à preservação. Essa situação é comprovada por não existirem nascentes preservadas, sendo a maior parte delas degradadas, com duas já sem vazão de água. Isso pode estar associado à "morte" da nascente, por afetar drasticamente a hidrologia do manancial ou por um nível freático tão baixo a ponto de cessar o fluxo. Deve-se ter em vista a época de coleta de dados deste estudo, que podem ter sido diretamente proporcionais à ausência de sua devida APP, uma vez que o tipo e porte da vegetação da cobertura do solo têm efeito sobre o deflúvio da água tanto nas nascentes (OLIVEIRA et al., 2014) como na qualidade da água (MARMONTEL; RODRIGUES, 2015), o que pode limitar seu uso. 
Apesar de ser importante manter a nascente preservada para a manutenção de suas características hidrológicas, conflitos entre o uso do solo e as diversas atividades humanas nessas áreas são comuns em diversas bacias hidrográficas, criando uma forte pressão antrópica e uma condição de degradação das nascentes, como visto por Ferreira et al. (2011) e Magalhães et al. (2012). Esta condição de degradação nas nascentes analisadas está associada, principalmente, à criação de ovinos e bovinos, característica da área de estudo, bem como de práticas agrícolas de subsistência.

Esse processo de degradação afeta, consequentemente, a riqueza de espécies nessas áreas, pois o uso para agricultura e pastagem desmata a mata ciliar, reduzindo o número de indivíduos e espécies e afetando a ecologia da flora na região. Isso é verificado pela baixa diversidade florística observada, pouca quantidade de indivíduos em cada nascente e alta densidade de espécies exóticas.

No semiárido, essa condição se torna ainda mais preocupante e pode afetar a segurança hídrica da região. Tendo em vista a questão pluviométrica da região, a oferta de água já é limitada. Também, falta contato da população com práticas conservacionistas do solo na bacia hidrográfica do rio Itapicuru, o que culmina em utilização inadequada dos corpos hídricos a ponto de se canalizar o fluxo das nascentes, realizar plantios agrícolas ou, até mesmo, atividades de piscicultura, como visto na Tabela 2.

A situação atual das nascentes na área estudada mostra que a legislação não está sendo seguida. Sendo assim, devem haver práticas de manejo dos recursos hídricos, que podem servir até como fonte de renda a partir de programas de pagamento por serviços ambientais (LIMEIRA et al., 2015; ROSA et al., 2016), além de aplicação da lei ambiental nas bacias rurais e informação adequada das propriedades para que seja verificada se há exigência ou não das APPs, assim como se há cumprimento ou não dessa norma (CAMPAGNOLO et al., 2017).

\section{CONCLUSÕES}

- O estudo identificou a situação ambiental das nascentes da região semiárida analisada. Alerta-se para as práticas inadequadas das áreas de seu entorno, que deveriam estar preservadas, mas estão em crescente ou pleno estado de degradação, com alta pressão das atividades humanas.

- A partir dessa condição, verificou-se a falta de gestão dos recursos hídricos voltada às nascentes por meio da aplicação do manejo de bacias hidrográficas. O cenário torna-se crítico tendo em vista não somente a região climática em que estão distribuídas, com períodos de baixa pluviosidade, como também a importância de se manter esse manancial hídrico em bom estado de conservação.

- Portanto, atividades de recuperação florestal das nascentes georreferenciadas, com monitoramento das demais fontes hídricas na bacia hidrográfica do rio Itapicuru, são indicadas para favorecer a preservação das nascentes, garantir o fluxo contínuo da água e, assim, a manutenção da sua atividade tanto ecológica quanto hídrica e hidrológica, estando disponível para o uso correto pela população local.

\section{REFERÊNCIAS}

ALMEIDA, A.S. de; VIEIRA, I.C.G. Conflitos no uso da terra em áreas de preservação permanente em um pólo de produção de biodiesel no estado do Pará. Revista Ambiente \& Água, Taubaté, v. 9 n. 3, p. 476 - 487, 2014. doi: 10.4136/ambi-agua.1410.

ALVES, T.L.B.; AZEVEDO, P.V. de; SANTOS, C.A.C. dos. Influence of climate variability on land degradation (desertification) in the watershed of the upper Paraíba River. Theoretical and Applied Climatology, v. 127, n. 3 - 4, p. 741 - 751, 2017. DOI: https://doi.org/10.1007/s00704-015-1661-1.

APG IV. ANGIOSPERM PHYLOGENY GROUP IV. An update of the Angiosperm Phylogeny Group Classification for the Orders and Families of Flowering Plants, APG IV. Botanical Journal of the Linnean Society, v. 181, n. 1, p. 1 - 20, 2016.

BAHIA. Lei $\mathbf{n}^{\mathbf{0}}$ 10.431 de 20 de dezembro de 2006. Dispõe sobre a Política de Meio Ambiente e de Proteção à Biodiversidade do Estado da Bahia e dá outras providências. Disponível em: <http://www.legislabahia.ba.gov.br/verdoc.php?id=64087\&voltar=voltar>. Acesso em: 23 dez. 2017.

BAHIA. Lei no 11.612 de 08 de outubro de 2009. Dispõe sobre a Política Estadual de Recursos Hídricos, o Sistema Estadual de Gerenciamento de Recursos Hídricos, e dá outras providências. Disponível em:< http://cbhsaofrancisco.org.br/wp-content/uploads/2012/05/LEI-N\%C2\%BA-11.612-DE-08-DE-OUTUBRO-DE2009.pdf>. Acesso em: 23 dez. 2017.

FLORESTA, Curitiba, PR, v. 48, n. 2, p. 245-254, abr/jun 2018

Jesus. J. B. et.al. 
BRASIL. Lei $n^{\circ} 12.651$, de 25 de maio de 2012. Dispõe sobre a proteção da vegetação nativa; altera as Leis nos 6.938, de 31 de agosto de 1981, 9.393, de 19 de dezembro de 1996, e 11.428, de 22 de dezembro de 2006; revoga as Leis nos 4.771, de 15 de setembro de 1965, e 7.754, de 14 de abril de 1989, e a Medida Provisória no 2.166-67, de 24 de agosto de 2001; e dá outras providências. Diário Oficial da União, Brasília, DF, vinte cinco de maio de 2012. Disponível em: <http://www.planalto.gov.br/ccivil_03/_ato2011-2014/2012/lei/112651.htm>. Acesso em: 04 set. 2017

CAMPAGNOLO, K.; SILVEIRA, G.L. de; MIOLA, A.C.; SILVA, R.L.L. da. Área de preservação permanente de um rio e análise da legislação de proteção da vegetação nativa. Ciência Florestal, Santa Maria, v. 27, n. 3, p. 831 - 842, 2017.

CASTRO, P. S; LOPES, J. D. S. Recuperação e conservação de nascentes. CPT: Série Saneamento e Meio Ambiente, n. 26, 2001, 84p.

EMBRAPA. Embrapa Solos UEP Recife, 2006. Disponível em: <www.uep.cnps.embrapa.br/solos/>. Acesso em: 24 set. 2017.

FERREIRA, R.A.; AGUIAR NETTO, A. de O.; SANTOS, T.I.S.; SANTOS, B.L.; MATOS, E.L. de. Nascentes da sub-bacia hidrográfica do rio Poxim, estado de Sergipe: da degradação à restauração. Revista Árvore, Viçosa, v. 35, n. 2, p. $265-277,2011$.

INSA. Instituto Nacional do Semiárido. Sistema de Gestão da Informação e do Conhecimento do Semiárido Brasileiro. Disponível em: <http://sigsab.insa.gov.br/acervoDigital>. Acesso em: 23 dez. 2017.

INEMA. Instituto do Meio Ambiente e Recursos Hídricos. CBH Itapicuru. Secretaria do Meio Ambiente do estado da Bahia. Disponível em:<http://www.inema.ba.gov.br/gestao-2/comites-de-bacias/comites/cbhitapicuru/>. Acesso em: 24 set. 2017.

LIMEIRA, M.C.M.; PINHEIRO, N.V.; SILVA, T.C. da; FILGUEIRA, H.J.A.; BARBOSA, J.M. Métodos de pagamento por serviços ecossistêmicos: aplicações em área de nascentes na bacia do rio Gramame, PB. Gaia Scientia, João Pessoa, v. 9, n. 1, p. 156 - 163, 2015.

LORENZI, H. Árvores Brasileiras: manual de identificação de plantas arbóreas do Brasil. Nova Odessa: Instituto Plantarum, v.1, $5^{\circ}$ ed., 2008, 384p.

LORENZI, H. Árvores Brasileiras: manual de identificação de plantas arbóreas do Brasil. Nova Odessa: Instituto Plantarum, v.3, $5^{\circ}$ ed., 2009, 384p.

MARMONTEL, C.V.F.; RODRIGUES, V.A. Parâmetros Indicativos para Qualidade da Água em Nascentes com Diferentes Coberturas de Terra e Conservação da Vegetação Ciliar. Floresta e Ambiente, Rio de Janeiro, v. 22, n. 2, p. 171 - 181, 2015. DOI: http://dx.doi.org/10.1590/2179-8087.082014.

MAGAlHÃES, L. T. S.; GOMES, J. B. V.; VASCO, A. N.; AGUIAR NETTO, A. O.; FERREIRA, R. A. Caracterização geo-pedológica das áreas de nascentes na bacia hidrográfica do rio Piauitinga, Sergipe, Brasil. Revista Ambiente \& Água, Taubaté, v. 7, n. 1, p. 169- 181, 2012. DOI: http://dx.doi.org/10.4136/ambi-agua.767.

OLIVEIRA, A.S. de; SILVA, A.M. da; MELLO, C.R. de; ALVES, G.J. Stream flow regime of springs in the Mantiqueira mountain range region, Minas Gerais State. CERNE, Lavras, v. 20 n. 3, p. 343 - 349, 2014. DOI: 10.1590/01047760201420031268.

PETTA, R.A.; CARVALHO, L.V. de; ERASMI, S.; JONES, C. Evaluation of Desertification Processes in Seridó Region (NE Brazil). International Journal of Geosciences, v. 4, p. 12 - 17, 2013. DOI: http://dx.doi.org/10.4236/ijg.2013.45B003.

PINTO, L. V. A.; BOTELHO, S.A.; OLIVEIRA-FILHO, A.T. de; DAVIDE, A.C. Estudo da vegetação como subsídios para propostas de recuperação das nascentes da bacia hidrográfica do Ribeirão Santa Cruz, Lavras, MG. Revista Árvore, Viçosa, v. 29, n. 5, p. 775 - 739, 2005.

PURIFICAÇÃO, C. G. C. da; SOARES, R. S.; JESUS, M. H. de; SALlES, L. de Q.; GONÇALVES, T. dos S. Hidrogeologia da bacia hidrográfica do rio Itapicurú-BA, como subsídio para o plano diretor de bacias. Revista Águas Subterrâneas, suplemento, Anais do XIX Congresso Brasileiro de Águas Subterrâneas, p. 1-20, 2016. 
ROSA, F.S.; TONELLO, K.C.; LOURENÇO, R.W. Eleição de áreas prioritárias para pagamento por serviços ambientais: uma análise em nível de microbacia. Revista Ambiente \& Água, Taubaté, v. 11, n. 2, p. 448 - 461, 2016. DOI: http://dx.doi.org/10.4136/ambi-agua.1809.

SANTANA, N.R.F.; AGUIAR NETO, A.O.; SILVA, M.G. da; GARCIA, C.A.B. Índice de qualidade da água nas nascentes do rio Piauitinga-se por análise multivariada e o uso na irrigação. Revista Brasileira de Agricultura Irrigada, Fortaleza, v. 10, n. 6, p. 999 - 1010, 2016.

VENZEL, S.M.; PAIXÃO, M.V.S.; PAIXÃO, G.P.; PAIXÃO, P.P. Revitalização de nascentes. Natureza on line, Santa Teresa, v. 14, n. 2, p. 1 - 6, 2016.

VIEIRA, R. M. S. P.; TOMASELLA, J.; ALVALÁ, R. C. S., SESTINI, M. F.; AFFONSO, A. G.; RODRIGUEZ, D. A.; BARBOSA, A. A.; CUNHA, A. P. M. A.; VALLES, G. F.; CREPANI, E.; OLIVEIRA, S. B. P. de; SOUZA, M. S. B. de; CALIL, P. M.; CARVALHO, M. A. de; VALERIANO, D. M.; CAMPELLO, F. C. B.; SANTANA, M. O. Identifying areas susceptible to desertification in the Brazilian northeast. Solid Earth, v. 6, p. 347 - 360, 2015. DOI:10.5194/se-6-347-2015. 
FLORESTA, Curitiba, PR, v. 48, n. 2, p. 245-254, abr/jun 2018

Jesus. J. B.. et.al. 